Outros Tempos, vol. 19, n. 33, 2022, p. 18-35. ISSN: 1808-8031

DOI: http://dx.doi.org/10.18817/ot.v19i33.907

\title{
ALBERTO SALLES, PENSAMENTO EDUCACIONAL E AÇÃO POLÍTICA NO BRASIL DE FINS DO SÉCULO XIXI
}

\author{
ALBERTO SALLES, EDUCATIONAL THOUGHT AND POLITICAL ACTION IN \\ BRAZIL AT THE END OF THE 19TH CENTURY
}

\section{ALBERTO SALLES, PENSAMIENTO EDUCATIVO Y ACCIÓN POLÍTICA A FINALES DEL BRASIL DEL SIGLO XIX}

\author{
RUBENS ARANTES CORREA \\ ORCID: http://orcid.org/0000-0003-0095-7534 \\ Doutor em História pela UNESP/FRANCA \\ Professor do Instituto Federal de São Paulo/Campus Birigui \\ Birigui/São Paulo/Brasil \\ rubens.arantes65@gmail.com
}

\begin{abstract}
Resumo: O artigo pretende discutir a trajetória e a produção intelectual de João Alberto Salles (18571904), membro da chamada geração 1870 que construiu toda sua carreira como homem de letras e da política em São Paulo. Sua obra abrange especialmente estudos de natureza sociológica, ciência política, direito e propaganda republicana nos quais emprega as matrizes filosóficas que marcaram a esmagadora maioria dos intelectuais brasileiros entre a segunda metade do século XIX e as primeiras décadas do século XX: o positivismo comteano e o cientificismo spencereano. No âmbito desse trabalho pretende-se enfatizar as concepções educacionais presentes no pensamento de Alberto Salles procurando articulá-las com a crise do Império e a nascente República. Em termos metodológicos, o trabalho lança mão das contribuições de Jean François Sirinelli que para abordagem dos intelectuais faz uso das noções de sociabilidade, itinerários e microclimas.
\end{abstract}

Palavras-chave: Intelectuais. Ação Política. Pensamento Educacional.

Abstract: The article intends to discuss the trajectory and intellectual production of João Alberto Salles (1857-1904), a member of the so-called 1870 Generation who built his entire career as a man of the literature and politics in São Paulo. His work especially covers studies of sociological nature, political science, law and republican propaganda in which he employs the philosophical matrices that marked the overwhelming majority of Brazilian intellectuals between the second half of the nineteenth century and the first decades of the twentieth century: Comtean positivism and Spencerian scientism. Within the scope of this work, it is intended to emphasize the educational conceptions present in the thinking of Alberto Salles, seeking to articulate them with the crisis of the Empire and the rising Republic. In methodological terms, this work makes use of the contributions of Jean François Sirinelli, who uses the notions of sociability, itineraries and microclimates to approach intellectuals.

Keywords: Intellectuals. Political Action. Educational Thought.

Resumen: El artículo pretende discutir la trayectoria y producción intelectual de João Alberto Salles (1857-1904), miembro de la llamada generación 1870 que construyó toda su carrera como literato y político en São Paulo. Su obra abarca especialmente los estudios sociológicos, las ciencias políticas, el derecho y la propaganda republicana en los que emplea las matrices filosóficas que marcaron la abrumadora mayoría de los intelectuales brasileños entre la segunda mitad del siglo XIX y las

\footnotetext{
${ }^{1}$ Artigo submetido à avaliação em agosto de 2021 e aprovado para publicação em dezembro de 2021.
} 
Outros Tempos, vol. 19, n. 33, 2022, p. 18-35. ISSN: 1808-8031

primeras décadas del siglo XX: el positivismo comteano y el cientifismo spenceriano. En el ámbito de este trabajo, se pretende enfatizar las concepciones educativas presentes en el pensamiento de Alberto Salles, tratando de articularlas con la crisis del Imperio y la naciente República. En términos metodológicos, el trabajo aprovecha las aportaciones de Jean François Sirinelli, quien utiliza las nociones de sociabilidad, itinerarios y microclimas para acercarse a los intelectuales.

Palabras Clave: Intelectuales. Acción Política. Pensamiento Educativo.

\section{Introdução}

A história intelectual e dos intelectuais do Brasil oitocentista e primeiras décadas do século XX é marcada por intensas controvérsias, polêmicas e participação de homens de letras na vida política nacional daquele período histórico de transição da monarquia para a república e do trabalho escravo para o trabalho assalariado. Participar e intervir na realidade ganham um caráter de urgência e dever de consciência assumidos pelos intelectuais, ainda que dispondo de espaços restritos de atuação.

Os anos 1870 marcam, entre outros fatos, a emergência de uma nova geração de intelectuais alinhada aos modismos filosóficos reunidos em torno dos cientificismos e que servirão de aporte e referências teóricas para analisar a realidade e os problemas nacionais e propor projetos reformistas visando elevar o país à condição do progresso e da civilização. Ao mesmo tempo, a Monarquia sob Pedro II inicia seu processo de decadência, que levaria à queda definitiva em 1889, devida, em grande medida, às cisões políticas internas às elites imperiais e à manutenção de ideários e valores ancorados na tríade à época superada: catolicismo, romantismo e bacharelismo-liberal.

Dada as precariedades da vida intelectual em um país com grande população de analfabetos, ausência de sistema de educação, fragilidades de suportes culturais como bibliotecas, museus e livrarias, restava, então, aos que se dedicavam as letras duas saídas: a imprensa e a política. Nesse sentido, e como lembra Alonso (2002), é duvidoso falar de um campo intelectual autônomo no Brasil da segunda metade do século XIX, além de ser impossível separar "intelectuais" de "políticos":

No Brasil da segunda metade do século XIX não havia um grupo social cuja atividade exclusiva fosse a produção intelectual. A existência de uma única carreira pública centralizada no Estado, incluindo desde empregos no ensino até candidaturas ao parlamento, fazia da sobreposição de elites política e intelectual a regra antes que a exceção. (ALONSO, 2002, p. 30). 
Outros Tempos, vol. 19, n. 33, 2022, p. 18-35. ISSN: 1808-8031

Por outro lado, dada a restrita circulação de livros e a pequena recepção das obras publicadas, em função dos fatores mencionados acima, obriga que o exercício da atividade intelectual se dê através de jornais e revistas, condição que possivelmente explique a ampliação de publicações, não só na Corte, como em muitas outras capitais de províncias, alimentada, ainda, por um contexto de relativa modernização e melhoramentos dos espaços urbanos. Os jornais, portanto, tornam-se espaços relevantes para a circulação de ideias, correntes filosóficas, estéticas, doutrinais e literárias, além de veículo para intervenção nos debates públicos.

Outro efeito da proliferação da atividade jornalística é o de permitir a formação de núcleos e grupos de intelectuais e escritores em torno de um órgão, movidos por interesses e ideais comuns e com isso emprestando relativa coesão aos círculos. É o caso do jornal $A$ Província de S. Paulo, fundado em 1875 e que reuniu no seu entorno jornalistas, políticos e intelectuais como Francisco Rangel Pestana, Américo de Campos, Campos Salles, Prudente de Moraes, José Maria Lisboa, Francisco Quirino dos Santos, Américo Brasiliense, Luiz Pereira Barreto e João Alberto Salles, este último, objeto desse trabalho.

Alberto Salles integra os quadros da chamada sociabilidade republicana paulista, grupo formado por jornalistas, advogados, políticos e intelectuais com atuação pública ao longo das décadas finais do século XIX e as iniciais do século XX através da imprensa, da publicação de livros, da atividade educacional, da participação em congressos políticopartidários. Nesse sentido, tal como o espírito de época que contagiou a geração 1870, Alberto Salles fará parte de uma contra-elite intelectual responsável pela elaboração de repertório de oposição ao sistema político monárquico hegemônico e aos valores que lhes davam sustentação.

A produção bibliográfica sobre Alberto Salles ora o tem tomado como um "pensador político", ora como um "ideólogo da República", ora como membro de um movimento de "ilustração" que teria existido no Brasil entre a segunda metade do século XIX e as primeiras décadas do XX, ao estilo daquele outrora ocorrido na Europa oitocentista.

Após levantar toda a trajetória de Alberto Salles, envolvendo as origens familiares, o percurso escolar-acadêmico e a vida profissional, Ribeiro Júnior (1983) em seu Alberto Salles: trajetória intelectual e pensamento político abarca o que considera os aspectos fundamentais do autor de Sciencia Politica (1891), tomando-o como um "pensador político". De acordo com Ribeiro Júnior (1983), Alberto Salles, em sua “biografia intelectual”, “[...] localiza-se dentro da vida intelectual e da estrutura sócio-histórica de sua época", marcada 
Outros Tempos, vol. 19, n. 33, 2022, p. 18-35. ISSN: 1808-8031

pelo positivismo e pelo "liberalismo e o individualismo inglês", sobretudo, a partir de Stuart Mill e Herbert Spencer (RIBEIRO JÚNIOR, 1983, p. 152).

Mas é de Spencer, ou melhor, a partir de Spencer que, empregando fórmulas como organismo social, a instabilidade do homogêneo, a diferenciação e a relatividade do conhecimento, Alberto Salles irá se esforçar para conciliar as doutrinas contemporâneas sobre a ciência política. (RIBEIRO JÚNIOR, 1983, p. 153).

Ressalta Ribeiro Júnior (1983) que muito embora fosse "receptivo e aberto a muitas correntes" filosóficas, Alberto Salles pretendia criar uma teoria política que pudesse não só compreender a realidade nacional como propor um projeto de país que contemplasse reformas em diversos níveis, a começar pela "instrução pública". Nesse sentido, a filosofia política de Alberto Salles nada teria de revolucionária, mas sim, em conformidade com a perspectiva teórica comteana e spencereana, um processo meramente "evolutivo" em direção ao estágio do progresso e da civilização.

De acordo com Ribeiro Júnior (1983), na teoria política de Alberto Salles as noções de governo, estado, sociedade, sufrágio universal, partido político, descentralização política, federalismo, formas e regimes de governo são plasmados em leitura muito particular das filosofias científicas do século XIX.

Nesse sentido, Alberto Salles não foi um "produtor original de ideias", algo que não só ele não foi capaz de produzir como nenhum outro intelectual da geração 1870 o foi. Seu pensamento político-social, assim como de todos os demais membros de sua geração, marcou-se pelo ecletismo, ou seja, uma forma instrumentalizada de se apropriar da diversidade de ferramentas teóricas oriundas da Europa e consumidas por todos os diferentes grupos de intelectuais interessados em conhecer, estudar e intervir na realidade nacional do tempo.

Washington Vita (1965), por seu turno, no trabalho Alberto Salles, ideólogo da República, situa-o como um "ideólogo acima de tudo" que trouxe relevante contribuição para a história das ideias políticas no Brasil. Localiza Alberto Salles no contexto do consumo, na América Latina, das doutrinas filosóficas provenientes da Europa no contexto do século XIX e suas diferentes formas de apropriações e aplicações por parte dos intelectuais brasileiros e latino-americanos.

Acentua o caráter eminentemente prático em Alberto Salles em relação ao consumo das doutrinas positivistas e organicistas, no sentido de que para o intelectual paulista urgia a construção, em bases científicas, de um sistema explicativo do aparelho político do 
Outros Tempos, vol. 19, n. 33, 2022, p. 18-35. ISSN: 1808-8031

Império, demonstrando suas inconsistências e suas inadequações para, em seguida, propor outro estado de coisas, baseado em instituições "cientificamente" modernas:

Ideólogo acima de tudo, e ideólogo republicano particularmente, Alberto Salles lançou mão de ideias para a sua ação política. Seja como cientista social ou cientista político, seja como cientista do Direito ou cientista da educação, sua única meta foi, através de ideias, não apenas entender a realidade brasileira, mas transformá-la. Nisto se resume seu engagement e sua mensagem. (VITA, 1965, p. 21).

\section{Trajetória(s)}

Nascido em Campinas em 24 de outubro de 1857, irmão de Manuel Ferraz de Campos Sales, que se tornaria presidente da República no quadriênio 1898-1902, Alberto Salles foi o mais jovem integrante de um grupo de intelectuais paulistas na conjuntura de fins do século XIX e inícios do século XX. Passa a infância em Campinas e já adolescente vai para São Paulo fazer preparatórios. Contrai matrimônio em 1882, mesmo ano em que conclui o curso de Direito, com Joana de Morais, filha de proprietários de terra na região de Rio Claro, interior de São Paulo.

Sua trajetória familiar é demonstrativa de uma sociabilidade típica de famílias economicamente emergentes, ligadas ao setor cafeeiro, em particular da região do oeste paulista, tendo por referência geográfica a cidade de Campinas. Como demonstram em seus trabalhos Carvalho (1990) e Alonso (2002), a condição de marginalização política e aos postos de comando do Estado, em que pese sua força econômica explica, em grande medida, a ação dessa elite emergente para a ação de confronto com o establishment imperial, incluso, as escolhas por ideias, doutrinas e filosofias de base política.

Em 1875 decide-se Alberto Salles pela Engenharia, indo para os Estados Unidos onde se matricula no Instituto Politécnico Rensselaer, de Troy, Nova York, permanecendo nos Estados Unidos ao longo dos anos letivos de 1875 e 1876. Nos Estados Unidos inicia suas leituras em Spencer, Comte e Littré, figuras exponenciais do pensamento filosófico daquele instante e de grande recepção, tanto no Brasil como nos Estados Unidos, e de Stuart Mill, filósofo clássico do liberalismo, além de enviar colaboração jornalística para A Província de São Paulo (sob o título geral Correspondências) ${ }^{2}$.

\footnotetext{
2 SALLES, Alberto. Correspondências - Troy, N.Y. A Província de São Paulo, ano 1, n. 101, 5 set. 1875 ; SALlES, Alberto. Correspondências - Troy, N.Y. A Província de São Paulo, ano 1, n. 204, 3 out. 1875; SALLES, Alberto. Correspondências - Troy, N.Y. A Província de São Paulo, ano 1, n. 288, 31 out. 1875; SALLES, Alberto. Correspondências - Troy, N.Y. A Província de São Paulo, ano 2, n. 490, 16 set. 1876;
} 
Outros Tempos, vol. 19, n. 33, 2022, p. 18-35. ISSN: 1808-8031

Em 1876 retorna ao Brasil e a partir de 1878 ingressa na Faculdade de Direito do Largo de São Francisco bacharelando-se na turma de 1882. Nesta fase teve intensa atividade jornalística, vinculando-se e integrando a redação de várias folhas acadêmicas, especialmente A Luta (1882), onde convive com Américo de Campos, Campos Sales e Rangel Pestana; A República (1876-1886); Opinião Republicana (1877), convivendo com Afonso Celso Júnior e Lúcio de Mendonça; O Federalista (1880) ao lado de Pedro Lessa e Alcides Lima; Evolução (1880), com Joaquim Francisco de Assis Brasil e Júlio Prates de Castilho; e Çà Ira (1882), ao lado de Raul Pompéia, futuro autor de $O$ Ateneu, clássico da literatura brasileira e fervoroso militante republicano.

A experiência junto à imprensa acadêmica permite a Alberto Salles aproximar-se dos temas mais candentes, além de construir afinidades ideológicas com outros intelectuais, ainda que em fase embrionária, aproximando-se de grupos políticos em formação. Sirinelli (2003, p. 231-269) observa que em seus processos de constituição, os intelectuais lançam mão de espaços de sociabilidade, como redações de jornais e revistas, nos quais constroem redes que lhes permitem inserirem-se na sociedade política.

A despeito do fato de os jornais acadêmicos, de um modo geral, terem vida efêmera, sua importância na cena cultural da cidade de São Paulo é fundamental para não só a sociabilidade entre seus membros como, também, para a veiculação da crítica ao sistema político monárquico, em novas bases teóricas referenciais, como atesta Antoniolli (2020), que em seu trabalho enfatiza o papel representado pelo jornalismo acadêmico praticado pelos estudantes da Faculdade de Direito do Largo de São Francisco, no contexto dos anos 18701880, no processo de reinterpretação e divulgação dos ideais republicanos.

Concluído o curso de Direito em 1882, Alberto Salles retorna a Campinas, abrindo escritório de advocacia e integrando a redação da Gazeta de Campinas - jornal surgido em 1869, congregando alguns membros da sociabilidade republicana paulista da segunda metade do século XIX e integrado, à época, por José Maria Lisboa (gerente) e Francisco Quirino dos Santos (redator-chefe).

Publica, no mesmo ano seu primeiro livro, Política Republicana ${ }^{3}$, uma obra de doutrina filosófica fruto, possivelmente, de sua experiência acadêmica, realizando um esboço

SALLES, Alberto. Correspondências - Troy, N.Y. A Província de São Paulo, ano 2, (número ilegível), 20 out. 1876.

${ }^{3}$ SALLES, Alberto. Política republicana. Rio de Janeiro: Tipografia de G. Leuzinger, 1882. 
Outros Tempos, vol. 19, n. 33, 2022, p. 18-35. ISSN: 1808-8031

de uma teoria política do positivismo brasileiro e propondo-se a construir uma exposição sistemática da doutrina republicana.

No livro, dividido em seis capítulos, Salles constata que o momento por que passa o país é de profunda agitação política e que tal situação poderia influenciar os republicanos a marcharem rumo a uma revolução, considerada por ele como um estado de anarquia mental. Era preciso, pois, que os adeptos da ditadura esclarecida e da ordem com progresso, ou seja, positivistas e republicanos, adotassem uma postura racional, subordinada a um corpo doutrinário de princípios fundamentais que regem a política (MARTINS, 2001, p. 138).

É com esse objetivo que Alberto Salles escreve, então, a Política Republicana, ou seja, com a finalidade de sistematizar o corpo de princípios necessários para a ação eficaz dos agentes políticos favoráveis à ordem e progresso e, contrários, ao retrógrado e revolucionário. Os seis capítulos que compõem o livro tratam, sob a ótica do positivismo, da origem do poder governamental, suas funções características e sucessivas evoluções até atingir a forma republicana; esboça uma teoria da organização científica do Estado, destacando a questão do federalismo e do sufrágio universal (MARTINS, 2001, p. 138-139).

Política Republicana aborda, ainda, a partir da formação positivista via Comte e Littré de seu autor, diversas questões que estão coladas à própria realidade nacional daquele instante histórico, não se tratando, portanto, de uma teorização abstrata e geral. Entre outros aspectos, trata das relações entre Igreja e Estado, questão sobre a qual Alberto Salles é enfático ao sustentar o princípio da secularização, além do fim de quaisquer formas de subvenção de instituições religiosas por parte do Estado; recorre à ciência para encontrar elementos legitimadores da república como forma legítima e segura de governo; estabelece analogias entre fenômenos e instituições sociais com as concepções desenvolvidas pela biologia (organização social); e defende, ainda, o processo evolutivo de transformação política, embora não descarte a possibilidade da via revolucionária (MARTINS, 2001, p. 139).

Alude ao sufrágio universal defendendo sua extensão a todos, incluindo mulheres e analfabetos, sustentando seu caráter direto e proporcional às classes sociais. Considera o regime monárquico como um sistema político condenado à morte, ao contrário da república federativa, símbolo da vida, do progresso e da ordem. Recomenda o modelo republicano norte-americano como o parâmetro a ser seguido no Brasil, sustentando, ainda, a existência de uma tradição republicana no Brasil, cujo curso natural seria alcançado a partir da evolução de eventos históricos antecedentes desde a Revolução Pernambucana de 1817 (MARTINS, 2001, p. 139-140). 
Outros Tempos, vol. 19, n. 33, 2022, p. 18-35. ISSN: 1808-8031

Outros dois problemas foram objeto de apreciação de Alberto Salles em Política Republicana: o problema da educação e a questão da mão-de-obra. A respeito do problema da educação lastimava o atraso em que se achava o sistema de ensino brasileiro até àquela altura, oferecendo dados tanto para o ensino superior quanto para o ensino primário como forma de mostrar o quanto a educação encontrava-se aquém das necessidades do povo brasileiro. Sobre a questão do trabalho, considerava a escravidão como um equívoco econômico, defendendo a imigração de trabalhadores livres e a adoção de leis que permitissem a naturalização e a extensão dos direitos políticos aos imigrantes.

Retorna a São Paulo em 1884 e adquire a co-propriedade de A Província de São Paulo, fato que motivou a saída de Américo de Campos e de José Maria Lisboa, muito provavelmente devido a desacordos políticos e de ideias. Em A Província de São Paulo, Alberto Salles responde pelas funções de redator, dividindo com Rangel Pestana as de gerente do veículo. Permanece, contudo, por pouco tempo, afastando-se do jornal da condição de proprietário, mas dando continuidade com a de colaborador.

Em A Província de São Paulo, Alberto Salles manteve colaboração regular desde os tempos em que fora estudante nos Estados Unidos, 1875, até bem próximo de seu falecimento, em 1904. Pelas páginas de A Província publica artigos que fazem uma radiografia dos acontecimentos, mas, também, textos de fundo doutrinário, de convicções pedagógicas e propaganda republicana.

Em 1885, Alberto Salles volta à carga com a publicação de Catecismo Republicano $^{4}$ (título que remete ao Catecismo Positivista de Auguste Comte, publicado em 1852), panfleto no qual o autor investe na defesa intransigente da separação entre Igreja e Estado. O opúsculo teve todo apoio e financiamento por parte do Partido Republicano de São Paulo, que mandou imprimir dez mil exemplares para distribuição gratuita. Trata-se de material de militância onde o autor oferece ao leitor de forma bem didática treze lições sobre noções básicas de política, envolvendo definições de Estado, formas de governo, Constituição, sufrágio eleitoral, federalismo, entre outros.

O pequeno manual de militância foi alvo de severa crítica do escritor, polemista e, também, republicano, Júlio Ribeiro, que em sua obra Cartas Sertanejas qualifica Alberto Salles como escritor malsucedido, e seu livro como amplo museu de monstruosidades evolucionistas (MARTINS, 2001, p. 221). Alberto Salles trava, então, uma polêmica com Júlio Ribeiro, respondendo a este com o livro Cartas a Júlio Ribeiro ${ }^{5}$, publicado no mesmo

\footnotetext{
${ }^{4}$ SALLES, Alberto. Catecismo republicano. São Paulo: Tipografia de Leroy King Bookwalter, 1885.

${ }^{5}$ SALLES, Alberto. Cartas a Júlio Ribeiro [por Demócrito]. São Paulo: Tipografia da "Província", 1885.
} 
Outros Tempos, vol. 19, n. 33, 2022, p. 18-35. ISSN: 1808-8031

ano de 1885 e impresso nas tipografias de A Província de São Paulo. Na realidade, a arte da polêmica foi uma prática constante entre intelectuais do século XIX, como demonstrado por Roberto Ventura em Estilo Tropical (1991).

Após deixar A Província de São Paulo, Alberto Salles, retorna a Campinas, para se dedicar ao magistério no Colégio Culto à Ciência, instituição escolar criada por irmandade maçônica frequentada pelos membros da sociabilidade republicana paulista, e onde já havia exercido funções de docente em anos anteriores. No ano seguinte publica o livro A Pátria Paulista, outra obra de militância em que tenta fundamentar em bases científicas as razões para o separatismo paulista.

Após a Proclamação da República, Alberto Salles continuará aliando ação e reflexão produzindo artigos para jornais, assumindo mandato de deputado federal pelo PRP (1893-1894) e direção da Escola Normal de São Paulo (1898-1901). Em 1891 publica Sciencia Politica, livro no qual submete a política ao crivo da ciência positiva, ou seja, tal como havia feito com a educação e com o direito em publicações anteriores, realiza uma reflexão sobre a política à luz do positivismo comteano e do organicismo spencereano, as duas matrizes doutrinais que marcaram toda sua vida intelectual.

Ao afirmar que a "política é uma ciência", estabelece uma simetria com as ciências biológicas compreendendo que assim como esta é a única autoridade científica a emitir juízo sobre os corpos e a anatomia animal ou vegetal, caberia à ciência política, em última instância, emanar o diagnóstico acerca da "anatomia do corpo nacional". Nesse sentido, a ciência política, no entendimento de Alberto Salles, teria por objeto o estudo do corpo da nação visando dar-lhe equilíbrio e bom funcionamento:

Assim como a anatomia geral ou compara classifica os seres na escala zoologia, pelos seus caracteres fundamentais de estrutura, distribuindo-os em grupos, ramos, ordens, famílias, gêneros e espécies, assim também deve a política classificar as nacionalidades, pelos seus caracteres fundamentais de estrutura. Há uma evolução política e social, assim como há uma evolução anatômica e biológica ${ }^{6}$.

O grande mérito de Alberto Salles com a publicação de Sciencia Política, de acordo com Cardim (1997), é o fato de ser o primeiro autor brasileiro a introduzir no país a ciência política como disciplina acadêmica, simultaneamente ao momento em que também iniciava sua trajetória em universidades europeias e norte-americanas. E, nessa linha,

\footnotetext{
${ }^{6}$ SALLES, Alberto. Sciencia Política [1891]. Edição fac-similar. Brasília, DF: Senado Federal, 1997. p. 89.
} 
Outros Tempos, vol. 19, n. 33, 2022, p. 18-35. ISSN: 1808-8031

prognosticava o autor que em pouco tempo, entre nós, a ciência política teria seu reconhecimento, pelas universidades, como força doutrinária "[...] regeneradora das sociedades contemporâneas"?.

Temperamento inquieto e espírito independente, vai romper com a República alinhando-se aos chamados "desiludidos da República", intelectuais que militaram ao longo da campanha em favor da causa republicana durante o Império e que, pouco tempo após a instalação do novo regime, vão se desencantar com os rumos tomados por ela. Entre 18 e 26 de julho de 1901 o jornal O Estado de S. Paulo, sob a direção de Júlio Mesquita, publica uma série de artigos intitulada Balanço Político - Necessidade de uma Reforma Política ${ }^{8}$, último trabalho de fôlego de Alberto Salles, no qual critica duramente a chamada Política dos Governadores implantada por seu irmão e presidente, Manuel Ferraz de Campos Salles. Pouco tempo depois, em 12 de março de 1904, veio a falecer, em Monte Alto, interior de São Paulo.

\section{Concepção de educação}

A preocupação com os problemas educacionais do país foi uma constante por parte dos membros da chamada Geração 1870, plataforma geracional de intelectuais brasileiros que dominou o pensamento nacional até pelo menos os anos 1920 e que um estudioso da história das ideias do período, Roque Spencer de Barros (1959), vai chamar de "ilustração brasileira".

A educação durante o Império, conforme aponta a historiografia da educação, foi quase que absolutamente negligenciada pelo Estado brasileiro, inexistindo um plano de abrangência nacional que pudesse contemplar, dentro de um sistema, as necessidades e particularidades de cada nível de ensino. Ensino primário insuficiente e pífio, ensino secundário desarticulado e com a mera função de encaminhamento dos estudantes para o ensino superior, ausência de métodos pedagógicos, formação insatisfatória de professores, eis o retrato educacional do Brasil sob o regime monárquico, já denunciado à época pelos próprios contemporâneos. Nem mesmo princípios básicos do liberalismo pedagógico como o da obrigatoriedade da educação, já introduzido em muitos países do ocidente, alcançou êxito.

\footnotetext{
${ }^{7}$ SALLES, Alberto. Sciencia Política [1891]. Edição fac-similar. Brasília, DF: Senado Federal, 1997. p. 297.

${ }^{8}$ SALLES, Alberto. Balanço político - necessidade de uma Reforma Política. O Estado de S. Paulo, ano 27, n. 8270, 18 jul. 1901. p. 1; SALLES, Alberto. Balanço político - necessidade de uma Reforma Política. O Estado de S. Paulo, ano 27, n. 8278, 26 jul. 1901. p. 1.
} 
Outros Tempos, vol. 19, n. 33, 2022, p. 18-35. ISSN: 1808-8031

O elitismo e o conservadorismo foram as marcas da educação monárquica como se pode perceber pelos estabelecimentos de ensino e pelos educadores referenciais da época. Abílio César Borges e seu Colégio Abílio, Ernesto Carneiro Ribeiro e seu Ginásio Carneiro Ribeiro, O Imperial Colégio Pedro II, os colégios fundados e mantidos por ordens religiosas católicas e protestantes, enfim, são exemplos de uma educação voltada exclusivamente para a formação de uma pequena parcela da sociedade.

É diante desse cenário que vai se posicionar Alberto Salles, que não chega a publicar obras especificamente tratando de educação ou da "instrução pública", como era comum se referir ao tema na conjuntura da segunda metade século XIX. Suas observações sobre a temática encontram-se dispersas em artigos de jornais e livros de militância política.

Em A Pátria Paulista ${ }^{9}$, originalmente de 1887 e publicado a propósito de sua campanha pelo separatismo, dedica um capítulo à educação intitulando-o Autonomia do Ensino, no qual é possível extrair alguns elementos constitutivos de seu pensamento educacional. Entendia que somente o desenvolvimento econômico não seria suficiente para elevar o Brasil ao patamar das nações de progresso e civilização, pois que sem "progresso moral e intelectual" proporcionado pela instrução o país continuaria patinando no atraso e na apatia.

Todavia, constata que "o regime centralizador do Império" impedia uma melhor “organização escolar” não só na província de São Paulo como, de resto, por todo território brasileiro. Critica a centralização excessiva, sobretudo, no que dizia respeito à "nomeação e escolha de professores", pois, identificava nessa prática a imposição da sujeição para fins eleitorais:

[...] continua-se a lamentar o nosso grande atraso moral e o completo abandono em que se acham as nossas escolas! Toda tentativa, porém, que visar descentralizar o ensino público, afastando-o da esfera oficial e procurando restituir ao professorado independência e autonomia, será sempre mal-vista pela administração e taxada de anárquica, de inconveniente e contrária aos preceitos da constituição do Império! Ninguém se lembra, contudo, de que assim procede a administração, unicamente para garantia de seus privilégios ${ }^{10}$.

E conclui conclamando por medidas que pudessem contemplar, ainda, o ensino em níveis secundário e superior, principalmente este último, para que as províncias pudessem

\footnotetext{
${ }^{9}$ SALLES, Alberto. A Pátria Paulista [1887]. Brasília, DF: Editora UnB, 1983.

${ }^{10}$ SALLES, Alberto. A Pátria Paulista [1887]. Brasília, DF: Editora UnB, 1983. p. 52.
} 
Outros Tempos, vol. 19, n. 33, 2022, p. 18-35. ISSN: 1808-8031

dispor de autonomia para a criação de cursos superiores que atendessem as necessidades locais em matéria de profissionais qualificados.

Um esboço de concepção de educação de Alberto Salles surge de forma mais delineada nas páginas de publicações como o Almanach Litterario de São Paulo e A Província de São Paulo / O Estado de S. Paulo em artigos publicados em diferentes momentos. Ainda quando estudante de engenharia nos Estados Unidos envia artigo para $A$ Província, publicado em 5 de setembro de 1875, no qual tece impressões sobre a educação dos negros após a Guerra Civil norte-americana, chamando a atenção para a necessidade da integração dos ex-escravizados à vida da cidadania proporcionada pela escola:

A educação dos negros torna-se matéria de imensa importância, quando sabemos que só no Sul há uma população de 4000.000 desses indivíduos. E pensar-se que todos são cidadãos, votantes, e influem senão direta ao menos indiretamente na política do país, faz-nos crer que a paz, a harmonia e a ordem da nação, muito dependem de sua completa educação ${ }^{11}$.

O tema da educação nos Estados Unidos será retomado novamente por Alberto Salles agora em artigo publicado pelo Almanach Litterario de São Paulo, em sua edição de 1878, no qual o autor estabelece as bases de seu pensamento educacional por toda sua trajetória. Atribui à educação os fundamentos para o desenvolvimento material e humano de uma nação, tendo por parâmetro a experiência histórica norte-americana. Tal premissa constituirá em base de um projeto civilizatório representado pelo grupo políticos e intelectuais do qual Alberto Salles integra:

É dela [da escola] que parte esplendida a luz da verdade e da certeza, para iluminar com seus raios divinos a senda infinita do progresso. É dela que nasce imprevista essa força misteriosa que conduz dos povos à conquista de um direito ou de um privilégio ambicionados, porque é dela que sai altiva a consciência da liberdade, o grandioso sentimento da igualdade e da fraternidade dos homens ${ }^{12}$.

Alberto Salles, no mesmo artigo, assinala, a título de comparação, a situação em que se encontrava a instrução pública nos Estados Unidos e no Brasil, revelando através de dados estatísticos, as diferenças de tratamento dado à questão da educação nos dois países para concluir que a Monarquia brasileira, diferentemente da República norte-americana, pouco ou nada havia feito desde a conquista da independência para tirar o país do atraso e do

\footnotetext{
${ }^{11}$ SALLES, Alberto. Correspondências - Troy, N.Y. A Província de São Paulo, ano 1, n. 101, 5 set. 1875. p. 2.

12 SALLES, Alberto. A instrução pública nos Estados Unidos e no Brasil. In: LISBOA, José Maria (ed.). Almanach Litterario de São Paulo para o ano de 1879. São Paulo: Tipografia da "Província”, 1878. p. 153.
} 
Outros Tempos, vol. 19, n. 33, 2022, p. 18-35. ISSN: 1808-8031

obscurantismo, preferindo amarrá-lo ao passado colonial e ao catolicismo romano. E arremata sua análise comparativa:

[Enquanto sobre] a nação americana visa a liberdade desde o berço, [...] pesavam em nossos braços as algemas do absolutismo português; é que a América sentiu logo a consciência de sua personalidade, ao passo que o Brasil foi sempre tratado como escravo. [...] E as causas de nosso atraso geral devem ser procuradas talvez no absurdo sistema de colonização adotado por Portugal, cujas consequências ainda perduram e que só à custa de muitos esforços poderão desaparecer ${ }^{13}$.

Em 1901, a propósito de sessão de formatura na Escola Normal (da qual era diretor nomeado), proferiu um discurso que, posteriormente é publicado por $O$ Estado em sua edição de 5 de dezembro, intitulado $O$ Ensino Público, no qual expõe alguns aspectos de sua concepção sobre o papel da escola e da educação escolar.

Inicia o artigo afirmando que a escola se constitui em um dos "órgãos mais importantes da nacionalidade", pois que dela se configura, por meio do ensino, a base da “consciência nacional”. Em seguida, passa a formular sua concepção de educação com base na "fecunda teoria da evolução" (inspirada no evolucionismo organicista de Herbert Spencer). Após fazer rápido esboço do desenvolvimento do ensino no Brasil havido até aquele momento, afirma que havia chegado o momento de uma nova orientação para instrução que levasse em conta o papel transformador da educação e a escola como "agente modificador":

A teoria evolucionista cujo critério fecundo vai modificando dia a dia as nossas mais antigas concepções [...] veio pôr termo [ao passado], afirmando categoricamente que a educação é de fato uma grande e poderosa força modificadora, capaz de produzir nas sociedades humanas transformações consideráveis e profundas, quando habilmente dirigida e organizada ${ }^{14}$.

Citando o filósofo alemão Leibniz recomenda que para a educação cumprir sua missão civilizadora e transformadora há que se aguardar, pacientemente, a ação do tempo, pois se trata de um projeto que requer esforço, vontade e crença na colaboração do tempo. Lembra, ainda, Alberto Salles, que existe uma correlação entre funções educacionais e estrutura política e recorre ao evolucionismo social para exemplificar sua tese: sociedades do tipo "militante" requerem da escola formação mais física, daí o preparo do atleta e do soldado; em sociedades do tipo "industrial", que seriam modelos desejados e evoluídos, a

${ }^{13}$ SALLES, Alberto. A instrução pública nos Estados Unidos e no Brasil. In: LISBOA, José Maria (ed.). Almanach Litterario de São Paulo para o ano de 1879. São Paulo: Tipografia da "Província", 1878. p. 160.

${ }^{14}$ SALLES, Alberto. O Ensino Público. O Estado de S. Paulo, ano 27, n. 8410, 5 dez. 1901. p. 1. 
Outros Tempos, vol. 19, n. 33, 2022, p. 18-35. ISSN: 1808-8031

educação torna-se mais "intelectual e moral”, assumindo função diversa daquela, pois que sua finalidade é a formação do operário e do artífice, do profissional e do artista.

Em seguida passa à análise da questão da liberdade de ensino, argumentando que embora a escola seja parte do aparelho estatal não cabe aos governos interferirem no funcionamento das instituições escolares, pois que tudo o que afeta direta ou indiretamente o ensino é de exclusiva competência dos agentes que atuam em seu meio. Ao Estado e aos governos estaria reservado o papel, em relação à educação, de regular e garantir as formalidades constitutivas como expedição de diplomas e organização dos estabelecimentos em níveis de ensino. Atribui, Alberto Salles, grande importância à liberdade de ensino e independência da escola, para que esta possa cumprir seu papel de agência formadora de consciências.

E por fim, depois de fazer longa digressão sobre teoria de pensadores referenciais da época como Spencer, Darwin, Comte, além de imersão por temas como raça e mestiçagem, conclui reafirmando o papel e a finalidade da escola:

[...] o ensino tem por fim [...] a formação de uma constituição mental média, base da consciência nacional. Ao aparelho escolar, portanto, que é o seu órgão permanente e legítimo, é que deve caber o emprego normal dos processos morais, que conduzem fatalmente à elaboração lenta, mas segura, dessa consciência coletiva, expressão viva da alma nacional ${ }^{15}$.

Toda concepção educacional de Alberto Salles estava, de acordo com Vita (1965), impregnada pela pedagogia cientificista de Herbert Spencer, na qual o filósofo britânico cria uma hierarquia de saberes que deveriam ser priorizados no processo educacional. Partindo da definição de que a "ciência da educação" tem por finalidade a preparação do indivíduo para a vida, esta deveria, então, priorizar o que necessitaria ser ensinado em uma escala de cinco ordens: fisiologia, higiene, física e química enquanto campos do conhecimento que contribuem para a preservação da vida; em seguida, o ensino das ciências que permitem melhor conhecimento dos alimentos; depois, o domínio do saber destinado a oferecer a melhor educação dos filhos; seguidamente, pelo ensino formador do cidadão; para, finalmente, a aquisição do conhecimento voltado para o cultivo do "ócio do espírito", representado pelo saber literário e artístico. Tratava-se, portanto, de uma pedagogia pragmática, na qual a formação moral e do bem-estar pessoal tinham mais relevância.

Tendo isso como parâmetro, Alberto Salles vai propor para o caso brasileiro uma reforma da instrução pública que levasse em conta não só a finalidade do ensino como os

${ }^{15}$ SALLES, Alberto. O Ensino Público. O Estado de S. Paulo, ano 27, n. 8410, 5 dez. 1901. p. 2. 
Outros Tempos, vol. 19, n. 33, 2022, p. 18-35. ISSN: 1808-8031

meios pelos quais deveriam ser seguidos para se atingir. Compreendendo a educação como uma ferramenta de mudança - "moral e mental" -, ao mesmo tempo, complexa e indispensável, afirma:

Não é certamente uma tarefa insignificante procurar levantar o nível intelectual e moral dos povos, derramando prodigamente a instrução por todas as camadas sociais, esclarecendo as consciências na justa compreensão das realidades da vida e abrindo a todas as carreiras, a todas as vocações diversas, uma porta franca de ingresso à conquista de todas as posições ainda as mais eminentes ${ }^{16}$.

Ao debater-se sobre a questão do ensino público, Alberto Salles retoma o problema da liberdade de ensino, tema que abordou em diversos momentos de sua obra. Alia, em defesa do ensino público, leigo, gratuito, científico e profissional, a indispensável liberdade de ensino, pois que contrário seu desenvolvimento pleno estaria comprometido:

Para o ensino público tomar, assim, um caráter social, é preciso, todavia, que ele seja absolutamente livre ou descentralizado, gratuito ou generalizado, leigo ou absolutamente neutral e integral ou científico e profissional [...] o ensino deve ser generalizado por tal forma que todas as classes sociais encontrem igualmente as mesmas facilidades para instruir-se e enriquecer o seu cérebro de noções úteis e indispensáveis à sua evolução mental. Tanto o pobre como o rico devem usufruir este grande benefício que nos trouxe a civilização contemporânea, com a menor soma possível de sacrifícios ${ }^{17}$.

O problema da educação na segunda metade do século XIX será um dos pilares, em termos de repertório, do pensamento da chamada geração 1870 , estando presente em opúsculos, artigos, conferências, livros, não sendo, portanto, preocupação exclusiva de Alberto Salles. Além disso, colocar a questão do ensino no centro do debate público era uma forma de combater o sistema político monárquico, causador, segundo os membros dessa contra-elite intelectual, do atraso do Brasil, alijando o país de estar presente no concerto das nações civilizadas. Nesse sentido, para Alberto Salles e demais membros da geração 1870 na perspectiva da filosofia cientificista, educação era a alavanca para elevar o Brasil ao progresso material e civilizacional. Para tanto, urgia a organização de um sistema de ensino.

\section{Considerações finais}

Alberto Salles pertenceu a uma geração de intelectuais brasileiros que tomou para si o papel da ação política como um dever urgente e imediato. Impulsionados pelo desejo de

\footnotetext{
${ }^{16}$ SALLES, Alberto. Sciencia Política [1891]. Edição fac-similar. Brasília, DF: Senado Federal, 1997. p. 27-28.

${ }^{17}$ SALLES, Alberto. Sciencia Política [1891]. Edição fac-similar. Brasília, DF: Senado Federal, 1997. p. $36-37$.
} 
Outros Tempos, vol. 19, n. 33, 2022, p. 18-35. ISSN: 1808-8031

intervir na realidade política e social em que se encontravam inseridos procuraram, ao longo das últimas décadas do século XIX e as primeiras do século XX, construir projetos e interpretações do Brasil à luz de uma leitura muito própria das doutrinas filosóficas importadas da Europa.

Traçou um percurso típico do intelectual brasileiro daquela plataforma geracional. Oriundo de família emergente da região do oeste paulista ligada ao setor cafeeiro, segue itinerário acadêmico próprio de membro das classes sociais abastadas, com incursão em instituição acadêmica do exterior e culminando com a formação em Direito pela Faculdade do Largo de São Francisco.

Alia sua trajetória intelectual imersa no jornalismo e no ensino com a ação política militando pela causa republicana e tomando parte em congressos, reuniões e conferências. Toda sua produção intelectual em livros e em artigos para imprensa está colada à realidade brasileira, levando-o a uma reflexão sobre os problemas nacionais à luz de uma leitura muito heterodoxa das matrizes filosóficas comteana e spencereana. Seu projeto político republicano era manifestamente reformista e elitista, avesso a qualquer tentativa de ruptura mais radical no processo histórico.

Acreditava no papel mobilizador e transformador da educação no sentido da formação moral dos indivíduos, única ferramenta, no seu entendimento, capaz de forjar gerações de brasileiros conscientes e aptos para o exercício da política e das atividades prático-profissionalizantes. Em seu repertório, como de resto no repertório dos demais membros de sua geração, a educação elevaria o país ao amadurecimento civilizatório, passo indispensável para o ingresso do Brasil no seleto grupo das nações progressistas e civilizadas.

\section{Referências}

\section{Documentos}

SALLES, Alberto. Correspondências - Troy, N.Y. A Província de São Paulo, ano 1, n. 101, 5 set. 1875.

SALLES, Alberto. Correspondências - Troy, N.Y. A Província de São Paulo, ano 1, n. 204, 3 out. 1875.

SALLES, Alberto. Correspondências - Troy, N.Y. A Província de São Paulo, ano 1, n. 288, 31 out. 1875.

SALLES, Alberto. Correspondências - Troy, N.Y. A Província de São Paulo, ano 2, n. 490, 16 set. 1876. 
Outros Tempos, vol. 19, n. 33, 2022, p. 18-35. ISSN: 1808-8031

SALLES, Alberto. Correspondências - Troy, N.Y. A Província de São Paulo, ano 2, (número ilegível), 20 out. 1876.

SALLES, Alberto. A instrução pública nos Estados Unidos e no Brasil. In: LISBOA, José Maria (ed.). Almanach Litterario de São Paulo para o ano de 1879. São Paulo: Tipografia da "Província", 1878. p. 150-178.

SALLES, Alberto. Política republicana. Rio de Janeiro: Tipografia de G. Leuzinger, 1882.

SALLES, Alberto. Cartas a Júlio Ribeiro [por Demócrito]. São Paulo: Tipografia da "Província", 1885.

SALLES, Alberto. Catecismo republicano. São Paulo: Tipografia de Leroy King Bookwalter, 1885.

SALLES, Alberto. Balanço político - necessidade de uma Reforma Política. O Estado de $S$. Paulo, ano 27, n. 8270, 18 jul. 1901.

SALLES, Alberto. Balanço político - necessidade de uma Reforma Política. O Estado de $S$. Paulo, ano 27, n. 8278, 26 jul. 1901.

SALLES, Alberto. O ensino público. O Estado de S. Paulo, ano 27, n. 8410, 5 dez. 1901.

SALLES, Alberto. A Pátria Paulista [1887]. Brasília, DF: Editora UnB, 1983.

SALLES, Alberto. Sciencia Política [1891]. Edição fac-similar. Brasília, DF: Senado Federal, 1997.

\section{Bibliografia}

ALONSO, Ângela. Ideias em movimento: a geração 1870 na crise do Brasil-Império. São Paulo: Paz e Terra, 2002.

ANTONIOLLI, Juliano Francesco. Um passado republicano para chamar de seu: a reescrita da história nacional pela geração 1870 da Faculdade de Direito de São Paulo (1870-1880). História Unisinos, v. 24, n. 1, p. 54-66, 2020.

BARROS, Roque Spencer Maciel de. A ilustração brasileira e a ideia de universidade. Boletim da Faculdade de Filosofia, Ciências e Letras da USP, São Paulo, n. 241, 1959. (História e Filosofia da Educação, n. 2).

CARDIM, Carlos Henrique. Alberto Salles: um século de Ciência Política no Brasil. In: SALLES, Alberto. Sciencia Politica [1891]. Edição fac-sim. Brasília, DF: Senado Federal, 1997. p. III-XXV.

CARVALHO, José Murilo de. A formação das almas: o imaginário da República no Brasil. São Paulo: Companhia das Letras, 1990.

MARTINS, Wilson. História da Inteligência Brasileira (1877-1896). 2. ed. São Paulo: T. A. Queiroz, 2001.v. 4. 
Outros Tempos, vol. 19, n. 33, 2022, p. 18-35. ISSN: 1808-8031

RIBEIRO JÚNIOR, João. Alberto Salles: trajetória intelectual e pensamento político. São Paulo: Convívio, 1983.

SIRINELLI, Jean-François. Intelectuais. In: RÉMOND, René (org.). Para uma História Política. 2. ed. Rio de Janeiro: Editora FGV, 2003. p. 231-269.

VENTURA, Roberto. Estilo tropical: história cultural e polêmicas literárias no Brasil, 18701914. São Paulo: Companhia das Letras, 1991.

VITA, Luís Washington. Alberto Salles, ideólogo da República. São Paulo: Companhia Editora Nacional, 1965. 